\title{
SOBRE CULTURA
}

\author{
About culture
}

RESUMO O entendimento do que seja cultura é o objeto desta exposição. Apresentam-se diversas abordagens sobre seu significado, criticando sua objetividade. Propõe-se, a seguir, uma abordagem centrada no eu, isto é, nas pessoas reais, evidenciando que tudo, que é feito, é feito por um sujeito. A cultura faz-se, pois, como respostas que os sujeitos, em relação uns com os outros, dão às necessidades vividas.

Palavras-chave: Cultura. Sujeito. Relação. Respostas.

ABSTRACT The object of this paper is the understanding of what culture is. We present several approaches about its meaning, analysing their objectivity. Our proposal is centred on the self, that is, the real people, showing that everything that is done, is done by a subject. Culture is understood, therefore, as responses that subjects, in relation to each other, give to the needs that they experience.

KEY-WORDS: CULTURE. SUBJECT. RELATION. RESPONSE.

\section{INTRODUÇÃO}

$\mathrm{O}$

que se entende hoje por cultura? Quero neste ensaio apresentar uma série de argumentos que levem o leitor a pensar e, talvez, repensar a compreensão do que seja isto que chamamos de cultura. Minhas reflexões se baseiam em interpretação que fiz de vários autores que abordaram o tema. Não discuto com eles, mas o leitor observará contestações frequentes, em busca de um olhar que atenda à vida plena.

Não desconsidero a contribuição que análises antropológicas, sociológicas, filosóficas, religiosas, estéticas, biológicas, fisiológicas trouxeram para o tema. Elas nos permitem sentir o quão misterioso é o ser. A cultura, no entanto, não se resume a tais aspectos. Ela tem que ser tomada como a forma de ser, na sua última apresentação. Em sendo processo, a forma acontece em trans-formação. Como a transformação se faz sempre à base da forma atual, vigente, observamos nesse processo a permanência de uma semelhança. Essa permanência não tem data de validade: pode durar milênios e se pôr sempre presente. Isto abre o caminho para descrever a cultura em seus traços como que permanentes. Estas ideias orientam a abordagem.

Kroeber \& Kluckhohn escreveram em 1952 o livro Culture: $a$ critical review of concepts and definitions, em que trazem mais de 150 definições. Dividem-nas em seis categorias: descritiva, históri-

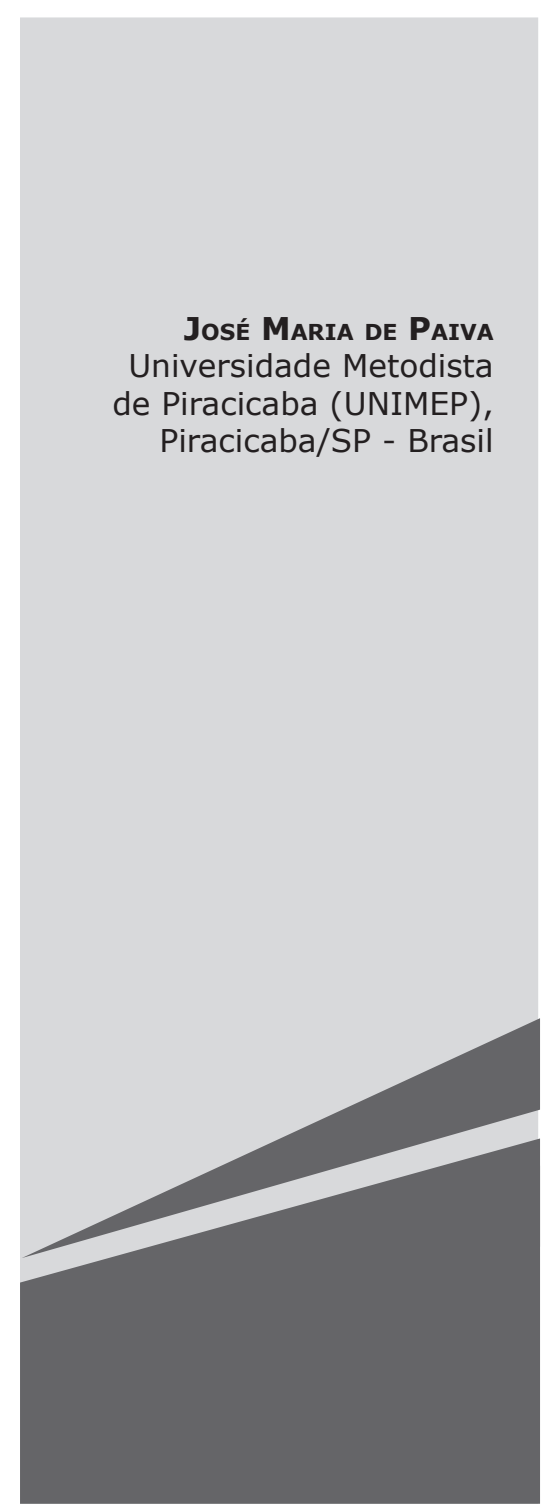


ca, normativa, psicológica, estrutural e genética. Dou, a seguir, um exemplo de cada tipo. Abordagem descritiva:

Cultura ou civilização ... é aquele conjunto complexo que inclui conhecimento, crença, arte, lei, moral, costume e algumas outras capacidades e hábitos adquiridos pelo homem como membro de uma sociedade. (E.B. TAYLOR, 1871, 1) (43)

Esta definição teve grande repercussão nos estudos antropológicos. De um lado, acentua a diversidade de aspectos que a vida humana compreende e, de outro, a condição essencial: a pertença a uma sociedade. Sociedade era entendida como algo para além dos indivíduos, com consistência própria. Ver Durkheim.

Abordagem histórica:

Cultura ... consiste naqueles padrões relativos ao comportamento e aos produtos da ação humana que podem ser herdados, isto é, passados de geração em geração independentemente dos genes biológicos. (PARSONS, 1949, 8) (48)

Cada geração recebe da geração anterior seu modo de conceber e praticar a vida. Há, pois, uma continuidade e um progresso. A tradição - e aqui prepondera a origem latina - entrega, negando qualquer ingerência biológica. Não há, pois, determinismos, aliás de nenhuma espécie.

Abordagem normativa, insistindo sobre o caráter modelar:

O modo de vida seguido pela comunidade ou pela tribo é considerado cultura ... inclui todos os procedimentos sociais estandardizados ... uma cultura tribal é (...) o agregado de crenças e procedimentos estandardizados seguidos pela tribo. (WISSLER, 1929, 15, 341) (50)
Abordagem psicológica:

Pode-se dizer que a cultura de uma sociedade consiste nas formas características em que as necessidades básicas dos indivíduos são satisfeitas naquela sociedade, isto é, consiste nas sequências de respostas particulares das várias famílias de comportamento que ocorrem numa sociedade. (MORRIS, 1946, 205) (56)

Abordagem psicológica é aquela que se centra na experiência que o eu, sujeito, tem em aprendendo. O eu não é abstrato: ele se envolve, todo, com a realidade vivida por seu contexto, por seu grupo de convivência. Como isto acontece para ele? Psicologia não é mais um campo de estudo: ela se refere à vivência que o eu tem, vivência no contato com os outros eus, eles também se pondo inteiros na experiência da vida.

Abordagem estrutural:

Cultura é um sistema de padrões de resposta de hábito inter-relacionado e interdependente. (WILLEY, 1929, 207) (61)

Estrutura significa a disposição das partes no todo, ou seja, observa o que compete a cada parte e como isso se combina nas ações das pessoas. Oferece a figura de sistema, insistindo na força de permanência dos comportamentos que atendem à continuidade e melhoramento da vida.

Abordagem genética,

Cultura é a soma total de tudo que é artificial'. É o equipamento de instrumentos e hábitos de vida, que foram inventados pelo homem e então passados de uma geração para outra. (FOLSOM, 1928, 15) (64)

Artificial, literalmente o que é feito pela arte (Houaiss: habilidade ou disposição dirigida para a execução de uma finalidade prática ou teórica, realizada de forma consciente, controlada e racional). É neste sentido que o termo é aqui empregado. 
Esta abordagem enfatiza a cultura como um produto ou artefato. Segundo os autores (61), diz-se genética porque todas as definições desse campo focam a questão: como a cultura chegou a ser? Quais os fatores que fizeram possível a cultura ou causaram sua existência?

Em todas estas definições a cultura é apresentada como resultado - todo o processo entendido como produção - ou como aquilo que os homens fizeram para viverem juntos e, nesta condição, como passível de ser transmitida. Faz-se objeto, ou seja, alguma coisa que está posta diante de; no caso, diante das pessoas reunidas entre si. Enfatiza-se o objeto e se deixa de lado o sujeito. Há, além disto, uma ênfase na distinção entre natureza e cultura. Essa distinção é muito frágil: a natureza, ela é, toda, concebida culturalmente. Não há natureza "pura”. Ela é criada pelo eu² é, portanto, cultural. Há, paralelamente, uma outra distinção: material e espiritual.

Quero, pois, propor uma nova conceituação de cultura. Parto do eu como princípio ${ }^{3}$ de toda a realidade: tudo que se põe é posto por pessoas, por eus. As coisas 4 , uma vez postas, não se tornam autônomas, independentes, objetivas. Elas são repostas por outros eus, ao entrarem em contato com elas. Sem o eu não há realidade! Por isto, toda realidade tem um desenho diferente, segundo o eu que a põe. ${ }^{5}$ Esta tese tem que ser bastante refletida, verificada, pois propõe uma nova epistemologia.

\footnotetext{
2 Uso o pronome eu, porque ele põe o indivíduo em sua unidade e totalidade, na plena expressão de vida. Algumas vezes uso do termo pessoa, que na linguagem cotidiana enfatiza o indivíduo real, único, levando por isto um nome.

3 Princípio se entenda, não como começo, mas como aquilo que dá origem $a$. O primeiro significado se refere à sucessão no tempo; o segundo, ao processo de causalidade. Em Grego se diz apxń/arché.

4 Entenda-se por coisas tanto aquilo que faz parte da prática do eu, quanto aquilo que serve de mediação para o eu praticar.

5 Ortega (1966) começa seu livro com a seguinte afirmação: La vida humana es una realidad extraña, de la cual lo primero que conviene decir es que es la realidade radical, en el sentido de que a ella tenemos que referir todas las demás, ya que las demás realidades, efectivas o presuntas, tienen de uno u outro modo que aparecer en ella.. Chamo a atenção para "realidade radical". Todas las demás cosas, embora não o esteja explícito, são suas expressões.
}

Não existe "o" homem: existem pessoas, existem eus. As pessoas não são abstrações: elas têm um determinado corpo, elas têm costumes, valores, visões de mundo, elas estão em permanente contato com o outro, sejam outras pessoas, seja - retomando o termo provisoriamente - a natureza. O eu, com efeito, nunca se sabe dividido. Tudo o que chamamos de "outro" nada mais é do que explicitação do eu, recebendo, pois, sua forma. O eu é!

O é (o ser), o existir, o viver - que são termos abstratos - têm que ser descritos em sua concretude histórica, como ação ${ }^{6}$. O meu é, por exemplo, consiste nos pensamentos que tenho, no digitalizar esses pensamentos, no sentir a claridade da minha sala, no barulho que escuto do lado de fora, no desejo de comer alguma coisa, e assim vai. Eu não faço uma ação: eu sou uma ação! Se eu fizesse uma ação, haveria uma separação "essencial" entre o eu e a coisa. E não há! Tudo que há está no eu.

À sucessão dos atos vividos pelo eu, chamo de experiência ${ }^{7}$. Chamo de exibição ${ }^{8}$ a forma que o eu toma em se pondo através das ações.

6 Ser é, com efeito, a mais densa de todas as palavras, pois compreende todas as ações possíveis. Ser resume, assim, todos os verbos, que precisam ações distintas entre si, embora unas por serem ações do eu. A civilização ocidental ainda cultiva a imobilidade do ser, estabelecendo essências e acidentes. Ora, ser é processo contínuo. Prefiro, em vez de ser, usar "o é", não substantivando a palavra.

7 O que gostaria de dizer com experiência? É a transformação que sentimos estar acontecendo em nós, ao contato com o outro. Experiência - provavelmente

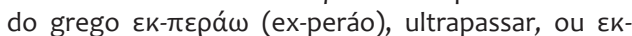
$\pi \varepsilon p a i ́ v \omega$ (ex-peraino), levar a termo, completar, ambos com a raiz $\pi \varepsilon ́ p a$ (péra), além de - indica um movimento que sai de $(\varepsilon \kappa)$ e vai além ( $\pi \varepsilon ́ p a)$, ultrapassando o que se é, e completando-se. Este sair de si e ir além, nós o vivemos, sem que seja preciso alguém a nos alertar a respeito. Experiência não deve, pois, ser tomada como adjetivação do sujeito, mas como sua própria substância.

8 A exibição está sempre condicionada ao hic et nunc. Em português, temos o verbo estar, que designa com exatidão a forma do ser, no momento em que se vive. Feliz expressão: o verbo estar denota, com mais precisão que o verbo ser, o processo que caracteriza o sujeito em ato. Somos, com efeito, processo. A cada passo, estamos. Somos, estando. O fenômeno designa, com precisão, a forma de estar do ser; não implica nem subentende acidente (em oposição a essência). 
Toda ação do eu é uma ação se sabendo; é o eu se sabendo. O saber não é, como acreditamos, produto intelectual: o saber é o se experimentar. O saber é a vivência da transformação de si (do eu), a tal ponto que, mesmo inconsciente (no entendimento freudiano), o eu passa a agir de acordo com a experiência vivida. Cada experiência o modifica, o faz diferente, no seu todo. Não há, portanto, acúmulo de experiência. Acúmulo é expressão quantitativa. A experiência é transformação qualitativa.

O eu age, se dá em atos, é ação. A ação do eu responde à necessidade de satisfação dos seus interesses. Entenda-se interesse no seu sentido radical de aquilo que importa $a$; aquilo que é preciso fazer para responder a situações concretas. Nesta delimitação, o interesse deve ser compreendido como necessidade. Por isto, o eu como que toma decisões a cada momento.

Gostaria de dizer: o corpo toma decisões, identificando o eu com o corpo. Com efeito, o eu não é dividido em corpo e alma. O corpo é animado, ele próprio é alma, em si mesmo; não é animado por outro. Esta divisão está enraizada na cultura ocidental: ela dificulta exacerbadamente a percepção/sensação da unidade do eu. Teríamos que nos acostumar a dizer "o eu", para não continuar a pensa-lo dividido.

O eu, não sendo abstrato, já nasce numa determinada forma. O que levou a que um eu tivesse esta ou aquela forma? Esta é uma questão sem resposta. Podemos levantar algumas hipóteses, mas o que levantarmos poderá, no máximo, fazer vislumbrar por que alguém é do jeito que é. Temos que partir do que está posto; buscar o conhecimento das pessoas em sociedade através da observação; e, daí, fazer uma descrição geral da sua cultura. Teríamos que descrever todas as expressões dos eus para desenhar a sua forma ou sua cultura. Forma, com efeito, designa a unidade de todas as expressões do eu: estas são constitutivamente o eu. Como as expressões

9 Alma, do Latim anima, como $\psi$ uxń/psyche em Grego, significa sopro, termo este designativo da vida. vão se sucedendo, o desenho vai se transformando a cada passo.

A cultura real está em contínua mutação. O que busco aqui, num plano teórico, é pensar como a cultura se estrutura. As culturas concretas exibem modalidades próprias no que toca aos mais diversos tipos de resposta que os eus dão às necessidades que se lhes apresentam. Não há como deduzir a cultura concreta de princípios teóricos. As teorias da cultura são construções que buscam a compreensão plausível da regularidade e compartilhamento de respostas.

Um dado do eu é estar sempre em relação com o outro. Os eus já nascem situados. O estar em relação com os põe em movimento. A relação não se põe do lado de fora, mas dentro. Quero dizer, o eu é, ele inteiro, voltado para o outro, devendo-lhe uma resposta $^{10}$. Cada eu se sabe em relação, se sabe num mundo circunstante, se sabe num mundo que contém o(s) outro(s). O outro é uma parte sua. Ser, de fato, é ser com o(s) outro(s), como a Fenomenologia já propôs. Isto não é magia filosófica: nós nos sabemos em permanente contato com o outro.

As pessoas, em se relacionando umas com as outras, se põem e põem, criam, uma forma comum de se pôr. Essa forma se estabelece por necessidade de harmonia, urgindo seu sentido etimológico de ajustamento: o viver-com implica em ajustamento, em todos os seus campos. Esta modelagem, imposta pelo ajustamento, se exibe em cada ato dos sujeitos, qualquer que seja a posterior tipificação do ato. Em outras palavras, as pessoas em relação sabem se pôr, com precisão, qualquer que seja a situação, entendendo o que está definitivamente em jogo é a vida, é o serem. A convivência faz comuns ação e reação, mas não necessariamente, os interesses. Em termos radicais não há estranhamento, ainda que haja diferenças e conflitos. Diferenças e conflitos, contudo, se operam no mesmo diapasão da cultura compartilhada.

10 Entenda-se por resposta a atitude de engajamento com o outro que se lhe põe à frente, independentemente do valor que a isto possa se atribuir. 
A relação propõe uma experiência, que cada um dos participantes vive a seu modo, sendo por ela trans-formado, ou seja, passando de uma forma para outra, gerando assim um novo desenho. Se não houvesse relação, não haveria transformação. A sucessão de desenhos dos eus em relação não obedece a regras impessoais, mas está toda afeta à qualidade ${ }^{11}$ de cada eu. O caminho da transformação é inventado ${ }^{12}$ em cada circunstância, obedecendo à forma de cada um e buscando a satisfação pessoal. Uma vez atendida a satisfação, a tendência é repetir o gesto em situações semelhantes. A regularidade de respostas cria o que chamamos de cultura, ou seja, o desenho compartilhado de entender a vida. Como não há padrão obrigatório de respostas às situações vividas, cada grupo social inventa o seu e responde como pode. Daí, a diversidade de culturas.

Assim, a cultura deve ser definida como a forma de ser socialmente compartilhada. A ênfase não recai sobre um desenho objetivo, do lado de fora, como se ele tivesse força para se impor. A ênfase recai sobre o eu, que se põe definitivamente como sujeito ${ }^{13}$, isto é, como fundamento da realidade, no entrelaçamento com os demais eus.

O compartilhamento, realizado nos contatos, supõe uma semelhança entre os eus que se relacionam. A semelhança é também um dado: não há por que explicar sua possibilidade. A experiência a diz. Se não houvesse assimilação ${ }^{14}$, não haveria convivência. Pela assimilação um eu se comunica com outro eu e, pela comunicação, se imitam

1 Segundo Aristóteles, entende-se por qualidade as propriedades de um ser, aquilo que faz daquele aquilo que ele é.

12 Inventar etimologicamente significa chegar $a$.

13 Sujeito, de sub jactum, lançado sob, posto sob, de tal forma que sobre ele se constrói a realidade. Não há realidade objetiva!

14 A assimilação consiste em fazer o outro entrar em mim, se con-formando com a minha forma. Simul, que deu origem a similis, significa junto; similis significa parecido. Ad similis e, daí, assimilação significa parecido com. [Em francês as duas palavras guardaram o mesmo radical: simul ficou ensemble e similis, semblable.] os gestos e, daí, os significados. ${ }^{15}$ A comunicação se faz assim condicionante da cultura. O que importa é entender que a comunicação abre caminho para o compartilhamento de significados, todo significado remetendo à vivência. A vivência é, de per si, significação (ação de significar).

Como os eus foram inventando significados? Sugiro um exercício de imaginação: tomemos os primeiros eus. Não sabiam nada! Não havia palavras! Tinham que viver! Ao se expressarem, por gestos, por urros, davam a perceber aos outros eus o que estavam vivendo. A repetição de uns e outros em situações parecidas levava a um código compartilhado. À medida que as experiências se diversificavam, aumentavam os componentes do código. Desta forma, ao longo de milênios, os eus desenvolveram seu modo de vida, nas mais variadas direções. Ao que possibilitou e sustentou essa comunicação dou o nome de significado.

Significado é a forma que o eu confere à coisa, agora feita signo. O significado não vem da coisa, mas do uso ${ }^{16}$ que dela faz o eu. Posso definir uso como a conveniência (de cum venire, um vir com, quase um encontro) da coisa com o meu próprio ser ou, mais sensivelmente, com o meu continuar a ser. As coisas se tornaram portadoras de significados. Isto afirma a inventividade humana. A coisa tal como ela é, é inacessível (problema puramente filosófico!). Ela é apropriada pelos eus para seu uso. A essa apropriação dou o nome de significação. A cultura se fez assim sinonímia de significação.

A significação se realiza, pois, em todas as expressões da vivência. Essas expressões são linguagem. Por elas dizemos aos outros; por elas os outros se dizem a nós. O dizer supõe comunidade. Se existisse só um eu, não haveria linguagem. Linguagem implica o outro. O dizer, que é ao mesmo tempo dizer-se,

15 Não há, pois, nem aquisição, nem entrega.

16 Uso não tem um sentido meramente mecânico. O significado é, assim, primeiramente utilitário, designando o aspecto pelo qual a coisa contribui para o viver, para o conviver. O significado tem, assim, o caráter eminentemente prático. 
dizer o mundo e dizer-se ao outro, explicita o real, formatando-o subjetivamente. ${ }^{17} \mathrm{O}$ que chamamos de sujeito e de objeto formam uma unidade transcendental, quase um a priori determinando a realidade unívoca do universo. Ortega $(1967,52)$ já escrevera: eu sou eu e minha circunstância.

No dizer-se, o eu usa de gestos e da palavra. Os gestos são movimentos corporais. A palavra é a mediação explicitadora das experiências vividas. Quero entender por gestos não só os movimentos corporais no sentido aceito pela sociedade hoje, mas ainda os produtos desses gestos, como a pintura, a música, a arte, a arquitetura, os sinais, textos escritos, a disposição das ruas na cidade, dos móveis na casa etc., enfim, tudo que nos põe à vista do outro. A palavra tem sido o instrumento privilegiado da comunicação. Gestos e palavra expõem o eu na sua realidade social.

A linguagem, tomada em seu sentido de dizer, se identifica com a cultura. Muitos autores, é verdade, delimitam a referência à linguagem à palavra oral e/ou escrita, fazendo dela o fulcro da cultura. Para além da palavra oral e/ ou escrita há, contudo, muitos outros tipos de expressão, todos eles sendo tão significantes quanto a palavra. Não dá para definir cultura por uma de suas partes, por isto a defino pelo seu todo: a forma de ser socialmente compartiIhada, o ser identificado com a realidade.

Este artigo nos obriga, assim, a uma reflexão sobre o real. Com efeito, se o real fosse algo em si, as diversas sociedades deveriam se encontrar no seu significado. Mas não é! Cada grupo social cria suas formas de viver, embutindo nelas sua compreensão, ou seja, seus significados, definindo o seu real. Os significados se põem no entendimento de vida que os eus, desse grupo ou daquele, produziram ${ }^{18}$.

17 Quero lembrar, aqui, o conteúdo expressivo de lógos,

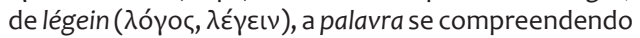
como explicitação do ser ou o ser se compreendendo como se dizendo. Daí, o significado de reunir, que o verbo tem: exibindo a unidade do ser, em movimento, ou seja, sempre o mesmo e sempre outro.

18 Produção vem de pro ducere, isto é, levar à frente. Não tem, pois, sentido de resultado mas de processamento. O progresso, ir/caminhar à frente, seria seu objetivo.
Sendo diferentes os significados, diferentes serão as culturas. Importa, sim, perceber que a diversidade de significados e culturas não procede do acaso, mas é decorrência da ação de construir a própria vida.

Só acompanhando a evolução da vida dos eus de uma sociedade é que comprovaremos esta asserção, dando conta do alcance dessa afirmação. Os significados e, portanto, as formas criadas de pôr a vida, não nasceram prontos: foram, literalmente, construídos no processo das relações (ações e reações). Teríamos que acompanhar esse processo para descrever as culturas postas. Não havia obrigação de serem de uma ou de outra forma: a forma foi se fazendo, às mais das vezes sem lógica que garantisse a programação de seu desdobramento e uma sequência. Pensar a cultura é, assim, mais do que estruturar um conhecimento sobre ela: é ir ao âmago do cotidiano, da vida real, dos modelos de relação praticados.

Geralmente se trata a cultura como algo pronto, que configura toda a ação humana, a ponto de se afirmar seu poder no processamento da vida. Este modo se distancia do que escrevi acima sobre a subjetividade, ela, sim, fundamento de todas as significações; significações que se extravasam nos atos praticados. A descrição de uma cultura deve observar o jogo das relações praticadas. $O$ jogo compreende disputa. Quem ganha o jogo, tem poder e, assim, força para fazer valer seus interesses e suas explicações, força para dar direção à sua sociedade. Descrever, pois, uma cultura só mesmo a posteriori.

\section{CONCLUSÃo}

Neste ensaio, enfatizamos o processo da sua estruturação. Esse processo se identifica com a forma de os eus se porem, uns em relação com outros. Tentamos enfatizar a unidade do eu, na diversidade das suas ações, dos seus atos; mostrar que todos os seus atos são corporais, não havendo lugar para distinção em atos materiais e atos espirituais. Toda análise, por mais teórica que se pretenda, tem em vista a compreensão da realidade social de 
que se faz parte. Nestes termos, se propõe a retomada da história das sociedades nas suas mais diferentes culturas, atentos ao processo de globalização que fere, muitas vezes no silêncio dos contatos, as raízes de entendimento da própria forma de ser.

\section{REFERÊNCIAS}

ELIAS, Norbert. O processo civilizador: uma história dos costumes. Rio de Janeiro: Zahar, 1990 GEERTZ, Clifford. A interpretação das culturas. Rio de Janeiro: Zahar, 1978

JULLIEN, François. $\mathbf{O}$ diálogo entre as culturas: do universal ao multilateralismo. Rio de Janeiro: Zahar, 2009

LARAIA, Roque de Barros. Cultura, um conceito antropológico. 14. ed. Rio de Janeiro: Zahar, 2001.

ORTEGA y GASSET, J. História como sistema, Mirabeau ou o Político. Brasília: Ed. UnB, 1982

ORTEGA Y GASSET, J. Meditações do Quixote. São Paulo: Iberoamericana, 1967.

SAHLINS, Marshall. Ilhas de História. Rio de Janeiro: Zahar, 1990 (1985)

WEBER, Alfred. Historia de la Cultura. México: Fondo de Cultura Economica, 1948 [1935]

WILLIAMS, Raymond. Cultura. Rio de Janeiro: Paz e Terra, 1992.

\section{Dados do Autor}

\section{JosÉ MARIA DE PAIVA}

Doutorado e pós-doutorado em Educação pela Universidade Estadual de Campinas. Campinas/ SP - Brasil.jmpaiva@unimep.br

Submetido em: 28-3-2016

Aceito em:8-2-2017 